\title{
NaVArro Beltrán, Enrique (2016) La Constitución Económica chilena ante los Tribunales de Justicia. Santiago de Chile: Ediciones Universidad Finis Terrae, 315 pp.
}

El Derecho Económico se hace presente en el debate jurídico chileno por intermedio del libro del profesor Enrique Navarro Beltrán, que se titula "La Constitución Económica chilena ante los Tribunales de Justicia".

El libro, prologado por Juan Colombo Campbell, ex presidente del Tribunal Constitucional, constituye un acabado examen sobre los fundamentos constitucionales de la actividad económica chilena. Trata la forma en que los tribunales de justicia han dado protección y amparo a los derechos fundamentales económicos. Bajo lo que el autor califica como la Constitución viva, aborda tópicos de reconocida relevancia como la libertad de empresa, la igualdad ante la ley, las cargas patrimoniales, el derecho de propiedad y la potestad sancionatoria administrativa. Se trata de temas de gran actualidad en Chile ya que se ha iniciado un proceso de reforma o sustitución de la Carta Fundamental que, en caso de llevarse a término, afectará la normativa constitucional económica, que muchos autores denominan Orden Público Económico.

Comienza el libro con la explicación de la libertad económica con la interrogante: ¿Neutralidad económica o Constitución valórica? Dentro de este primer capítulo, el autor se refiere al Derecho Comparado Europeo, y a la Constitución chilena en su normativa económica. Particularmente se detiene en el derecho a emprender una actividad económica y la regulación legal de dicho derecho.

En el segundo capítulo, el autor aborda el marco constitucional del Estado Empresario, su regulación normativa, y las exigencias para que el Estado pueda incursionar en actividades empresarias. De esta forma, el texto cita un fallo del Tribunal Constitucional relativo al artículo $19 \mathrm{~N}^{\circ}$ 21 que viene a ser una consecuencia del principio de subsidariedad, como también del deber del Estado de resguardar la igualdad de oportunidades (Fallo del Tribunal Constitucional rol No 167/1993). Dichos requerimientos, que se traducen en una autorización específica de una ley de quórum calificado, es según el autor, una concreción del discutido principio de subsidiaridad en nuestra Carta Fundamental. A juicio de Navarro el principio tiene como precedentes el Derecho Constitucional irlandés, las Encíclicas Papales y a partir de 1993, la Carta Fundamental peruana. Navarro recalca que la regla general que la actividad empresarial debe quedar entregada a los particulares, sin perjuicio de las excepciones en las que el Estado es empresario por expreso mandato constitucional, como en las relativas a las estaciones de televisión, las sustancias mineras no concesibles y la gran minería del cobre. Concluye el capítulo refiriéndose a la empresa pública y las sociedades estatales. 
En el capítulo tercero Navarro examina el principio de igualdad ante la ley. El tema se sustenta en la evolución que ha experimentado el principio, tanto en aquellas ocasiones que ha desechado las infracciones a la igualdad ante la ley, como aquellas que la ha declarado. La discriminación arbitraria, conforme la jurisprudencia citada, se debe asociar con la adecuada ponderación y razonabilidad de la misma, debiendo hacerse un test de proporcionalidad para su adecuada determinación. Agrega el profesor Navarro que la jurisprudencia ha experimentado una importante evolución en especial en lo que se refiere a las diferencias arbitraria, la proporcionalidad y particularmente la razonabilidad. Por eso, afirma el autor que en la Jurisprudencia del Tribunal Constitucional se ha evolucionado en la conceptualización de la igualdad ente la ley, no solo ya como prohibición de diferencias basadas en razones de sexo, estirpe o condición, sino también como igualdad entre iguales, esto es, entre los que se encuentran en la misma situación, a los que debe aplicarse el mismo estatuto jurídico. En ese sentido, se citan sentencias del Tribunal Constitucional roles No 28/1985, 53/1988, $1217 / 2008$ y $1254 / 2008$.

Con posterioridad, el capítulo cuarto se centra en los principios de Derecho Constitucional tributario. Analiza los principios de legalidad y el de no confiscación, para concluir con el principio de no afectación. Resulta destacable la noción extensa de tributo expuesta en el texto que incluye cualquier impuesto, contribución, arancel, derecho o tasa $y$, en definitiva, cualquier prestación que los particulares tengan que satisfacer al Estado. Igualmente la jurisprudencia ha dicho que el concepto de tributo debe considerarse como una carga patrimonial impuesta por el Estado para el cumplimiento de los fines propios del bien común. Concluye el autor indicando que del precepto constitucional se desprenden una serie de principios aplicables a los tributos, como el de legalidad, igualdad, no confiscación y no afectación.

A continuación se aborda el derecho de propiedad, su fortalecimiento, sus limitaciones y la expropiación como único medio para privar de la propiedad de un bien. El autor recoge algunos fallos que se refieren al derecho de propiedad, o los parámetros de sus limitaciones basados en la mesura y razonabilidad. En lo que respeta a este principio el Tribunal Constitucional ha ido estableciendo parámetros en materia de limitaciones, que el autor denomina "regulaciones mesuradas y razonables". Igualmente destaca la expropiación como único mecanismo tolerado para privar a una persona de su propiedad (Fallos del TC, roles $334 / 2001,505 / 2006,541 / 2006$ y 1215/2008).

En el siguiente capítulo, Navarro se refiere al debido proceso en la Jurisprudencia Constitucional, cuyos antecedentes remonta a las constituciones de 1833 y 1925 . El autor señala que el constituyente no ha definido los elementos específicos ni el deasorrollo determinado de 
un justo y racional procedimiento, delegando en el legislador la potestad para definir y establecer sus elementos. Las exigencias constitucionales en materia de justo y racional procedimiento son definiciones primarias del legislador complementadas con el desarrollo jurisprudencial de la cláusula del debido proceso. En este sentido se citan los fallos roles 432/2004 y 2111/2011, que han ido complementando el concepto normativo de debido proceso.

Concluye este riguroso trabajo con el análisis de la potestad sancionadora administrativa en la jurisprudencia constitucional en conformidad con el artículo 19 No 3 de la Constitución. Se trata de un aspecto o materia novedosa desde la perspectiva del Derecho Económico que debemos subrayar. La potestad punitiva administrativa, definida por el Tribunal Constitucional como "el poder con que actúan los órganos estatales no jurisdiccionales investidos de atribuciones para sancionar hechos ilcitos" debe basarse en los principios de la tipicidad, de legalidad, como lo destan diversos pronunciamientos jurisprudenciales como fallo del Tribunal Constitucional rol 479/2006, en lo que respecta a legalidad, y el fallo del Tribunal Constitucional rol 244/1996, en lo relativo a tipicidad.

Cada uno de los capítulos presenta un apoyo bibliográfico consistente y un esquema de análisis que lo lleva a terminar con conclusiones muy bien trabajadas. Se trata de una obra que nos va introduciendo gradualmente en el esquema regulatorio chileno logrando interesar al lector a pesar de tratarse de un tema en sí mismo arduo. A ello contribuye la utilización de un lenguaje directo y al propósito del escritor de enfrentar las dificultades abiertamente.

"La Constitución Económica chilena ante los Tribunales de Justicia", resulta ser un libro de utilidad para la cátedra de Derecho Económico actual, que ha ido adquiriendo cada vez mayor importancia. Esta obra puede abrir una ventana para vislumbrar la regulación y libre competencia del Derecho chileno.

\section{CARlos Ruiz-TAgLe ViaL*}

Licenciado en Ciencias Jurídicas de la Universidad de Chile, Doctor en Derecho de la Universidad de los Andes (Chile) y profesor de Derecho Económico de la Universidad Católica del Norte, con sedes en las ciudades de Antofagasta y Coquimbo. Correo electrónico: caruiz@ucn.cl 